\title{
ACUPUNTURA NA SAÚDE PÚBLICA: UMA REALIDADE HISTÓRICA E ATUAL PARA ENFERMEIROS
}

Leonice Fumiko Sato Kurebayashii'; Genival Fernandes de Freitas'; Taka Oguisso ${ }^{3}$

${ }^{\prime}$ Enfermeira. Acupunturista. Mestre em Enfermagem

${ }^{2}$ Doutor em Enfermagem, advogado, docente da Escola de Enfermagem da USP ${ }^{3}$ Doutora em Enfermagem, advogada, professora titular da Escola de Enfermagem da USP

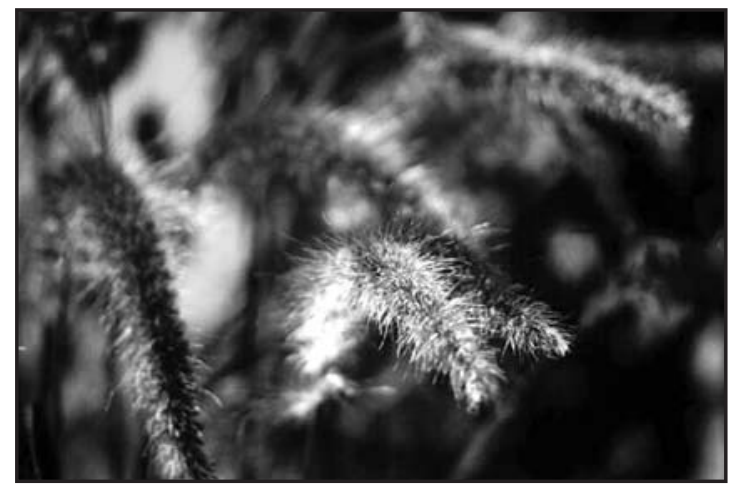

ACUPUNCTURE IN HEALTH PUBLIC SYSTEM: A HISTORICAL AND PRESENT REALITY FOR NURSES

\section{ABSTRACT}

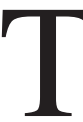

his research was performed with 33 nurses from 11 Health Units in São Paulo. This article aimed at identifying the perceptions of the nurses about the acupuncture practice. Interview data was analyzed based on Bardin (2004) and distributed within four categories: perceptions on acupuncture (1), difficulties (2), facilities in the acupuncture practice (3) and ethicallegal dilemmas (4). The results evidenced: credibility on technique (1); limiting factors, such as work overbook, lack of material and human resources and health policy (2); facilitating factors, such as: highly qualifying courses and implementation of acupuncture services by a multiprofessional team (3); and regarding the ethical-legal dilemmas, the opinion that not only physicians are entitled to exercise the acupuncture in the public health system.

Key words: Nursing, Public Health, Alternative Medicine, Acupuncture.
ACUPUNTURA EN LA SALUD PÚBLICA: UNA REALIDAD HISTÓRICA ACTUAL PARA ENFERMEROS

\section{RESUMEN}

$\square$ ste estudio tiene por objetivo identificar las -1 percepciones de los enfermeros acerca de la acupuntura. Investigación cualitativa exploratoria con 33 enfermeras, en 11 Unidades de Salud de São Paulo. Los datos fueron distribuidos en cuatro categorías: percepciones sobre acupuntura (1), dificultades (2) y facilidades (3) de la práctica de la acupuntura por la enfermería y dilemas éticos y legales (4). Los resultados demostraron: la credibilidad en el procedimiento (1); factores limitantes como sobrecarga de trabajo, falta de recursos materiales, humanos y política de salud (2); factores facilitadores como la posibilidad de capacitación e implementación de la acupuntura multiprofesional (3) y, finalmente, cuanto a los dilemas ético y legales, la opinión de que no solo los médicos deben ejercer la acupuntura en la red pública.

Palabras clave: Enfermería, Salud Pública, Medicina Alternativa, Acupuntura.

\section{RESUMO}

Desquisa qualitativa exploratória, com 33 enfermeiras em 11 Unidades de Saúde do Município de São Paulo, cujo objetivo foi identificar as percepções dos enfermeiros acerca da acupuntura. Os dados foram analisados com base em Bardin (2004) e distribuídos em quatro categorias: percepções sobre a acupuntura (1), dificuldades (2), facilidades da prática da acupuntura pela enfermagem (3) e dilemas ético-legais (4). Os resultados demonstraram: credibilidade na técnica 
(1); fatores limitantes como sobrecarga de trabalho, falta de recursos materiais, humanos e política de saúde (2); fatores facilitadores como a possibilidade de capacitação e implantação da acupuntura multiprofissional (3) e por fim, quanto aos dilemas ético-legais, a opinião de que não somente médicos devem exercer a acupuntura na rede pública.

Descritores: Enfermagem, Saúde Pública, Medicina Alternativa, Acupuntura.

\section{INTRODUÇÃO}

O presente estudo dá continuidade a uma prévia pesquisa realizada em três Unidades Básicas de Saúde, consideradas Pólos de Difusão da Medicina Tradicional Chinesa (MTC), em 2006, onde a acupuntura e outras terapias complementares já eram oferecidas à comunidade, desde a implantação do serviço em 2002 pela Secretaria Municipal de Saúde da Prefeitura do Município de São Paulo (SMS/PMSP). O intuito do estudo foi conhecer o interesse e a prática da acupuntura por enfermeiros que atuavam em unidades de Saúde Pública e realizar uma prévia discussão acerca da relevância ou não da temática para os enfermeiros dessas unidades.

A terapia da acupuntura tem uma longa história de utilização em diferentes sociedades e com certeza não foi necessariamente uma atividade realizada por um grupo restrito de profissionais. No Brasil, há plena aceitação pelos Conselhos que regulamentam as profissões da saúde sobre a prática da acupuntura. Apesar disso, dentro do programa de treinamento de profissionais nos Pólos de Difusão de práticas da MTC pela SMS/SP, organizados pelo Projeto de Implantação da MTC nas unidades de saúde, a partir de 2002, preferencialmente médicos foram treinados pela Associação de Medicina Tradicional Chinesa (São Paulo, 2002).

No decorrer do ano de 2006, porém, uma importante conquista foi obtida no campo da legislação em favor do exercício da acupuntura e de outras terapias complementares em caráter multiprofissional, com a Portaria $\mathrm{n}^{\circ}$ 971, de Maio de 2006, do Ministério da Saúde (MS) (Brasil, 2006). A discussão sobre a acupuntura continua acirrada, por meio de projetos de lei que visam à regulamentação da atividade, com a normatização de a quem compete o seu exercício. Entretanto, a classe médica por resoluções do Conselho Federal de Medicina (CFM), reivindica para a categoria, a exclusividade da acupuntura como ato médico.

Por outro lado, a implantação do SUS no Brasil, a partir da Constituição Brasileira, promulgada em 05 de outubro de 1988, trouxe um grande desafio para a enfermagem e para os enfermeiros: redirecionar suas práticas para o atendimento integral à saúde coletiva e individual da população brasileira (Brasil, 1988). Pode-se afirmar que o grande desafio coletivo dos enfermeiros inseridos no SUS para o século XXI é, portanto, recriar os cuidados de enfermagem para atingir a integralidade da assistência e transformá-los em um novo paradigma mobilizador das forças da vida individual e coletiva (Nuñez, 2002, p.48).

Neste contexto, cabe indagar se o enfermeiro que trabalha em unidades de saúde pública, em resposta aos novos desafios que se apresentam para sua atuação junto à população, compreende a acupuntura como uma possibilidade terapêutica em sua área. E ainda, será que está atualizado sobre os aspectos ético-legais que permeiam esses debates? Quais seriam as dificuldades ou facilidades que esses profissionais encontram em incorporar a acupuntura como realidade concreta no cotidiano de suas atividades em suas unidades? Quem seriam os profissionais aptos a realizarem a acupuntura em nosso país, segundo o ponto de vista das entrevistadas?

Essas discussões têm um caráter de urgência e os enfermeiros não podem ficar à margem dos debates, que interferem sobre atribuições profissionais, direitos e alcance de suas práticas de assistência à saúde. Esse estudo teve, portanto, o objetivo de conhecer as percepções dos enfermeiros em relação à acupuntura como técnica complementar à assistência de saúde; desvelar as incertezas, dificuldades, atitudes e percepções do enfermeiro com relação à acupuntura como prática da enfermagem, pós-Portaria 971/2006, com vistas a contribuir para uma implantação democrática, ética e multiprofissional da acupuntura no país.

\section{PERCURSO METODOLÓGICO}

Para atender aos objetivos propostos e desenvolver a temática em estudo, foi realizada uma investigação de natureza exploratória descritiva, 


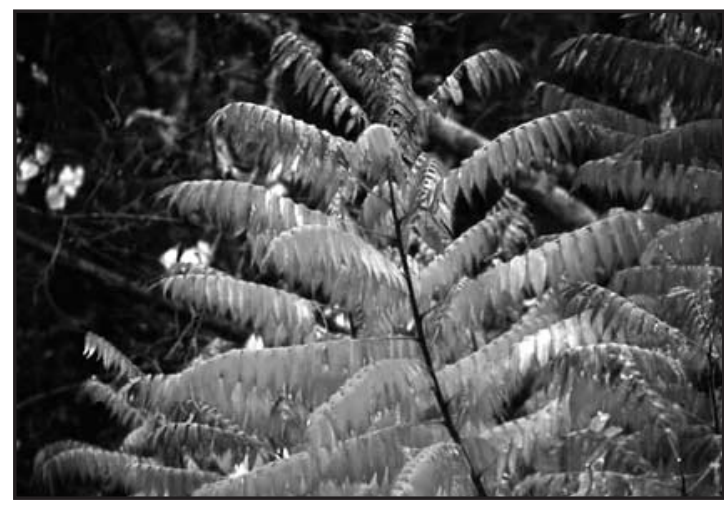

com utilização de uma entrevista pré-estruturada, gravada e transcrita, cujos dados foram analisados com base na Análise de Conteúdo de Bardin (2004), por compreender que esta metodologia permitiria descrever, interpretar e desvendar percepções e significações da acupuntura para os enfermeiros. O projeto foi aprovado pelo Parecer $n^{\circ} 104 / 07$ pela SMS/SP e os dados foram coletados após orientação, esclarecimento e assinatura do Termo de Consentimento Livre e Esclarecido.

\section{RESULTADOS E DISCUSSÃO}

Os resultados observados na análise lexical das 33 entrevistas revelaram a distribuição dos conteúdos em quatro categorias discursivas principais, em resposta às seguintes questões: (1) O que você acha da acupuntura como prática complementar na assistência à saúde? Fale sobre isto. (2) Que fatores dificultam ou facilitam a prática da acupuntura pelo enfermeiro? E nesta Unidade? Fale um pouco sobre isso. (3) Em sua opinião, quem deveria exercer a acupuntura? Fale sobre isto.

Para melhor visualização e compreensão das Categorias e Subcategorias foi construída a Tabela 1 .

Em relação à Categoria I, na subcategoria 1, obtivemos opiniões que reforçam a importância da acupuntura como técnica complementar à assistência da saúde, para enfermidades crônicas e agudas e em especial, para diminuição e alívio de dores. Percebe-se aceitabilidade e crença na eficácia da acupuntura, ora por experiências prévias pessoais, de parentes e familiares, ora pela oportunidade de ouvir relatos de experiência de pacientes que estão ou estiveram em tratamento de acupuntura com os médicos acupunturistas das unidades de saúde em que as enfermeiras trabalhavam. Referem melhoria dos sintomas e bem-estar e destacam a importância dessa terapêutica como complementar a assistência da saúde, sugerindo que seja mais difundida para a população.

... Hoje a acupuntura já é vista como uma parte da medicina, ela... realmente tem tido bons resultados... principalmente aqui no ambulatório, temos acupuntura, é uma referência de acupuntura e tem como você ver a evolução do paciente, principalmente na questão das dores agudas, como complementar a doenças pré-existente.. (I.1.E25).

A acupuntura já é aceita em muitos países europeus e incorporada ao sistema oficial de saúde, tendo se tornado mais popular no Ocidente após aprofundamento dos estudos visando reconhecer seus mecanismos de ação pela comunidade científica. É uma das terapêuticas mais difundidas na Europa, tendo sido introduzida no Brasil, há 100 anos por imigrantes japoneses. A acupuntura, juntamente com a osteopatia e a homeopatia já está mais consolidada e organizada na sociedade européia, com essa prática coexistindo com a medicina alopática nos serviços de saúde regulamentadas por lei, com situação ética e política definidas. No Canadá e Estados Unidos observa-se um aumento na demanda de acupuntura, com experiências sobre a inserção de práticas terapêuticas não-alopáticas no ensino da área de saúde e no sistema de saúde (Carneiro \&Soares, 2004, p. 83).

Dentro da Categoria I, na subcategoria 2, encontramos opiniões sobre a acupuntura como uma técnica holística.

... Eu acho importantíssimo esse trabalho, porque vê o indivíduo integralmente... não é só trabalhar a queixa, conduta e sim trabalhar a causa, o que está acontecendo pra chegar numa determinada queixa ou patologia... a acupuntura veio para auxiliar e acho até resolver... a resolutividade mesmo no atendimento integral a esse indivíduo. (I.2.E16)

Etimologicamente, o termo holismo deriva do grego "holos", que significa, completo, total, inteiro. Concebido como um princípio absoluto, o 
holismo se contrapõe ao reducionismo, tornandose muito familiar nas terapias complementares, referindo-se a uma abordagem filosófica do cuidado de saúde apoiada no todo e não em partes. Essa abordagem não é exatamente um caminho novo, basta observar os sistemas de saúde de outras épocas e em outros contextos culturais, como por exemplo, a Medicina Tradicional Chinesa. Embora desenvolvidos em contextos culturais diferenciados, os sistemas ocidental e oriental para a saúde na Antigüidade eram ambos holísticos, tendo como base a assistência de saúde com foco sobre o todo do organismo, considerando-o como um microcosmo inserido no macrocosmo (Capra, 2004, p.299350) .

No campo da enfermagem, uma das teoristas que aborda a energia na construção de marcos conceituais é Martha Rogers (1970). O movimento em direção ao novo paradigma holístico leva as enfermeiras a buscarem fundamentos teóricos inovadores e Rogers, com o foco que dá ao ser humano integral, de sua interação com o meio ambiente, passa a ser um referencial de vital importância para embasar este novo olhar, saber e fazer nas interações enfermeiro-cliente.

Ainda na Categoria I, encontramos a subcategoria 3. Emerge uma importante opinião acerca dos benefícios da acupuntura, principalmente quanto às vantagens que a técnica apresenta no tratamento das doenças, por não se utilizar de medicações alopáticas e por vezes até suprimir ou diminuir a necessidade do uso dessas medicações, assim como os poucos efeitos colaterais que provocam.

Todas essas outras formas de... de... medicina alternativa, eu acho que elas precisam complementar mesmo a saúde, do atendimento. Eu acho que tem muita coisa que a alopatia não dá conta, né? Eu acho que a gente tem que cada vez procurar estas outras atividades. E principalmente porque o efeito colateral destas outras são infinitamente menores. (I.3.E15)

O aumento da utilização da acupuntura nos serviços de saúde já tem sido observado em diversos países do Ocidente, inclusive no Brasil e simultaneamente vivencia-se o crescente perfil demográfi- co da população idosa. A complexidade dos fatores que são inerentes ao envelhecimento leva à necessidade de se indicarem modalidades assistenciais multidisciplinares e, entre elas, a acupuntura (Góis, 2007, p.2).

Com relação aos fatores limitadores para o exercício da acupuntura pelo enfermeiro, surge na Subcategoria 1, da Categoria II, queixas sobre a sobrecarga de trabalho do enfermeiro e falta de recursos materiais e humanos.

... É a falta de pessoal... Porque a enfermeira, ela faz todos os papéis... na Unidade, além do papel de enfermeiro, de auxiliar, de técnico de enfermagem, de psicólogo, de tudo... de assistente social...(II.1.E3)

Em 1984, Oguisso já havia citado como obstáculos para as enfermeiras, que a não realização de atividades específicas dos programas de saúde e na assistência primária se devia à falta de pessoal e falta de área física (Nuñez, 2002, p.116). Na atual pesquisa, o quadro manteve-se inalterado. Indagase, diante do exposto, quanto tempo mais a enfermagem permanecerá distante da realização de atividades assistenciais na saúde pública, por não ter garantido o espaço físico, os recursos materiais e humanos?

A enfermagem possui contradições internas em seu saber/fazer sobre a assistência específica prestada pelo enfermeiro e as inúmeras atividades que acabam sendo exercidas, que nem sempre possuem relação com as suas atribuições ou com a clientela. Situações essas que acabam por determinar um cotidiano conflitante e por vezes, frustrante para os profissionais (Gomes \& Oliveira, 2005, p. 1011-1018).

Observamos ambigüidades e contradições vivenciadas pelas entrevistadas, quanto ao papel gerencial, administrativo ou, por vezes, burocrático, em detrimento da função assistencial direta com o usuário. O descontentamento com a estrutura e organização das unidades de saúde que privilegia e se centraliza na atividade médica quanto à distribuição e ocupação de salas em detrimento das atividades da enfermeira, que não tem valorizada a sua prática assistencial, parece ser um fator limitante para o exercício da acupuntura pelo enfermeiro. 
A Categoria III foi dividida em quatro subcategorias, a saber, a Subcategoria 1 referente à necessidade de formação, capacitação técnica e abertura de cursos reconhecidos de acupuntura para os enfermeiros e a dificuldade constatada, de que os cursos de acupuntura foram oferecidos somente para a classe médica, não estando abertos à enfermagem, nem a outros profissionais da rede pública de saúde, como podemos observar no relato a seguir.

...Primeiro, eu não sei se existem cursos assim... que possa ser feito por qualquer profissiona... Houve curso de acupuntura na rede, mas parece que foi só para profissional médico, pra enfermeiro, não... Já é uma coisa que dificulta, porque... dá oportunidade para alguns profissionais e não pra outros. O que facilitaria é que na rede pública fosse feito o curso, de especialização... (II.2.E28)

Em seguida, a Subcategoria 2, relacionada à necessidade da implantação do serviço de acupuntura pelo enfermeiro na Secretaria de Saúde; a Subcategoria 3, que destaca a importância da orientação da população sobre a acupuntura e seus benefícios e a necessidade de expansão dos serviços de acupuntura, em função da grande demanda nas unidades de saúde, onde a acupuntura já tem sido realizada; e, por fim, a Subcategoria 4, que estabelece como fator facilitador para a prática da acupuntura pelo enfermeiro, a proximidade que este já tem com o usuário e a característica de sua formação como profissional de saúde.

As reflexões acerca da incorporação da acupuntura como um novo saber e fazer para a enfermagem, a partir da vivência das entrevistadas, pautou-se na crença de que os enfermeiros são profissionais diferenciados em sua abordagem do processo saúde-doença, sendo elementos primordiais de transformação da população, por meio da orientação e comunicação que lhes confere proximidade, confiabilidade junto à população. São unânimes em afirmar que desde que tenham formação e capacitação técnica e que sejam implementados os serviços de acupuntura abertos às equipes multiprofissionais na rede pública de saúde, os enfermeiros estariam perfeitamente aptos para o seu exercício.
... Porque, a gente acompanha muito... e assim, a facilidade que o usuário tem de se abrir com o enfermeiro ... eu acho que seria até mais fácil... a gente está muito próxima deles... usa a mesma linguagem, vai na casa deles fazer visita domiciliar... Eu acho que eles têm uma facilidade maior para se abrir e para num tratamento (de acupuntura) seria muito bom. (III.4.E1)

Na Subcategoria 1, da Categoria IV, foram agrupados depoimentos que comentam a dificuldade do exercício da acupuntura pelos profissionais não-médicos, por ser considerada uma prática limitada ao médico, muito provavelmente, por desinformação ou por errôneas orientações veiculadas pelos meios de comunicação, pelos próprios profissionais médicos e pela estrutura do serviço público que não abre espaço ao enfermeiro.

... E o ato médico, taí uma questão que está começando a surgir, é porque antes não era... algo exclusivo do médico e agora parece que as coisas estão se encaminhando de uma forma que acabe virando um ato médico... (IV.1.E6)

$\mathrm{Na}$ análise de constitucionalidade do Ato Médico, o Projeto de Lei do Senado n $\infty$ 7.073/2006 (Brasil, 2006a), caso seja aprovado, poderá acarretar inúmeros problemas aos diversos profissionais da área da saúde, conferindo ao Conselho Federal de Medicina poderes amplos para definir o que é ato exclusivo do médico, concedendo um poder normativo do tipo penal. Entretanto, segundo o Art. $5^{\circ}$, Inc. XXXIX da Constituição Federal, não há "crime sem lei anterior que o defina, nem pena sem prévia cominação legal". E na ausência de lei, segundo o Art. 22.I da Constituição, cabe somente à União legislar sobre "direito civil, comercial, penal... e do trabalho". A competência para legislar sobre as atribuições profissionais é do Congresso Nacional, por meio de Lei Ordinária, a qual se refere a qualquer matéria e sua iniciativa segue o preceito constitucional (Oguisso \& Schmidt, 2007, p.221-234).

Sendo assim, compete à União criar legislação para regulamentar o exercício das profissões, não podendo, ser delegada essa incumbência a nenhum conselho de classe. Cabe ressaltar que os Conselhos Profissionais têm competência legislati- 
va limitada, pois a norma que deles emana, na modalidade de resoluções de classe, constitui um ato da administração de um colegiado, contendo esclarecimentos, soluções, deliberação, regulamentação ou determinação sobre algum assunto de interesse de determinada categoria profissional.

A Subcategoria 2, da Categoria IV, ressalta a importância do estudo e análise dos papéis que se atribuem à enfermagem, suas funções e as diferentes percepções que se têm quanto ao que o enfermeiro faz e pode fazer, como fatores que influenciam a aceitabilidade do exercício da acupuntura pela enfermagem, frente à população, aos demais profissionais e às instituições.

... eu acho que existe um pouco do preconceito... porque não é o médico que faz... e que é o enfermeiro que faz, o enfermeiro serve para fazer isso e não serve para fazer aquilo... esse é um dos fatores... o preconceito em relação ao enfermeiro. (IV.2.E2)

O debate acerca da condição de submissão, falta de autonomia e subserviência que muitas vezes emerge como perfil do profissional de enfermagem em relação ao profissional médico, ganha destaque neste estudo, em função dos dilemas ético-legais que perpassam o exercício da acupuntura em nosso país. Cabe salientar que as entrevistadas enfermeiras deste estudo eram todas do sexo feminino, confirmando a tendência histórica que ainda persiste de que a enfermagem é uma profissão eminentemente feminina.

$\mathrm{Na}$ Subcategoria 3, surgem os aspectos relacionados à regulamentação da prática da acupuntura pela enfermagem. A julgar pelas respostas, algumas entrevistadas desconheciam a acupuntura como especialidade da enfermagem. Achados semelhantes foram encontrados em estudo realizado por Nuñes (2002, p.87) sobre as Terapias Alternativas e Complementares (TAC) na enfermagem. Apenas 22,2\% das enfermeiras sabiam da existência de amparo legal para a prática das TAC e $77,8 \%$ desconheciam o respaldo legal e a Resolução COFEN 197/97 (COFEN, 2009).

Para finalizar, na Subcategoria 4, temos as opiniões sobre a quem se destinaria o exercício da acupuntura, segundo as entrevistadas, na Tabela 2.
Quanto à Categoria IV, podemos concluir que as entrevistadas, em sua totalidade, acreditam que a acupuntura poderia ser exercida pela enfermagem na Saúde Pública. Muitos depoimentos foram favoráveis à abertura da acupuntura para todos os profissionais da saúde de nível superior. Outros depoimentos consideraram importante que alguns profissionais, com atuação direta sobre a saúde física do paciente, seriam os profissionais para os quais a acupuntura como especialidade poderia vir a ser complementar em suas práticas assistenciais específicas. Dentre elas a enfermagem, pela amplitude de campos de atuação, poderia certamente ser uma dessas categorias profissionais, cuja instrumentação em acupuntura, reverteria em grandes benefícios à população. E por fim, alguns depoimentos foram favoráveis à atividade da acupuntura por todos os profissionais que estivessem preparados para tal e nessa categoria podemos incluir os praticantes de acupuntura, que não têm documentação de nível técnico ou superior, mas que obtiveram o conhecimento em cursos livres de formação de acupuntura, qualificações ou que haviam adquirido a técnica em outro país. Os praticantes de acupuntura orientais que no Brasil se instalaram nas últimas décadas estão também inseridos nessas categorias.

\section{CONSIDERAÇÕES FINAIS}

Vivemos, na atualidade, o desafio de tornar a acupuntura um exercício democrático e aberto a todo e qualquer profissional habilitado tecnicamente para tal. Almeja-se popularizá-la, elevando o número de profissionais capacitados, consequentemente, o número de pessoas atendidas, uma vez que já existe demanda para a acupuntura, segundo informações relatadas nessa pesquisa, nas unidades de saúde.

Entretanto, o saber e fazer do enfermeiro acupunturista na Saúde Pública ainda é um fruto por se colher e será decorrente de uma prática de cuidados que são pertinentes ao seu exercício profissional, de forma a constituir um fazer específico, adaptado à sua área de assistência e cuidados prestados. A acupuntura promove o bem-estar do todo do indivíduo, em suas dimensões física, psíquica e espiritual. Pode ser utilizada para enfermidades em graus diferenciados de gravidade, para prevenção 
de doenças e promoção à saúde, podendo ser exercida por distintos profissionais, respeitando especificidades e o âmbito de atribuições de cada profissional.

Para que o enfermeiro assuma o papel de acupunturista e para que possa contribuir para a implantação efetiva da acupuntura multiprofissional no Brasil, é necessário abandonar a alienação e a falta de interesse pelo novo, por meio da atualização constante dos aspectos ético-legais que permeiam sua profissão, encarando as vicissitudes de um tempo repleto de turbulências e desafios, assumindo o que lhe pertence por lei, mesmo que ainda não assimilado por completo. Um esforço reflexivo se faz necessário para que novos caminhos da prática e realização do cuidar sejam somados ao fazer do enfermeiro. A cultura profissional depende em grande parte do interesse e consciência daqueles que atuam e estão envolvidos no saber e fazer que caracteriza a profissão. Dessa forma, relações de submissão, temor, baixa auto-estima profissional e omissão não auxiliam na construção do que se apresenta como possibilidade presente: a incorporação efetiva do exercício da acupuntura ao saber e fazer do profissional enfermeiro no contexto da Saúde Pública.

\section{REFERÊNCIAS}

- Bardin, L. (2004) Análise de conteúdo. Lisboa: Edições 70.

- Brasil. Câmara dos Deputados. Sampaio B. Projeto de Lei 7.703/2006.[legislação na Internet]. Brasília:2006a. [citado 2007 set. 10]. Disponível em: http://www.camara.gov.br/sileg/ Prop_Detalhe.asp?id=339409
- Brasil. Constituição da República Federativa do Brasil, 1988. Brasília: Senado Federal; 1988.

- Brasil. Ministério da Saúde. Portaria n. 971/2006. Aprova a Política Nacional de Práticas Integrativas e Complementares (PNPIC) no Sistema Único de Saúde. Diário Oficial da União, Brasília, 4 maio 2006. Seção 1, p. 20-25.

- Capra F. (2004) O ponto de mutação. 24a ed. São Paulo: Cultrix; Holismo e saúde; p. 299-350.

- Carneiro MLM, Soares SM. (2004) Holismo e saúde: uma abordagem ampliada. In: Gualda DMR, Bergamasco RB. Enfermagem, cultura e o processo saúde-doença. São Paulo: Ícone; p. 73-92.

- Conselho Federal de Enfermagem (COFEN). Resolução COFEN 197/97. Estabelece e reconhece as terapias alternativas como especialidade e/ou qualificação do profissional de enfermagem [legislação na Internet]. Brasília; 1997. [citado 2009 set. 20]. Disponível em: http://www.portalcofen.gov.br/ 2007/materias.asp?ArticleID=7041\&sectionID=34 .

- Góis ALB. (2007) Acupuntura, especialidade multidisciplinar: uma opção nos serviços públicos aplicada aos idosos. Rev Bras Geriat Geront. 10(1):1-8.

- Gomes AMT, Oliveira DC. (2005) A auto e heteroimagem profissional do enfermeiro em saúde pública: um estudo de representações sociais. Rev Lat Am Enferm.13(6):1011-8.

- Nuñez, HMF. (2002) Terapias alternativas/complementares: o saber e o fazer das enfermeiras do Distrito Administrativo 71, Santo Amaro [dissertação]. São Paulo(SP): Escola de Enfermagem/USP; 152 p.

- Oguisso T, Schmidt MJ. (2007) O exercício da enfermagem: uma abordagem ético-legal. $2^{\text {a }}$ ed. Rio de Janeiro: Guanabara Koogan. Perspectivas sobre os rumos da enfermagem; p. 22134.

- Rogers ME. (1970) An introduction to the theoretical basis of nursing. Philadelphia: F. A. Davis.

- São Paulo (Cidade). Secretaria Municipal de Saúde. Caderno Temático em Medicina Tradicional Chinesa [texto na internet]. São Paulo; 2002. [citado 2009 set. 26]. Disponível em: http://ww2.prefeitura.sp.gov.br//arquivos/secretarias/saude/ar eas_tematicas/0047/MTC_CadernoTematico.pdf

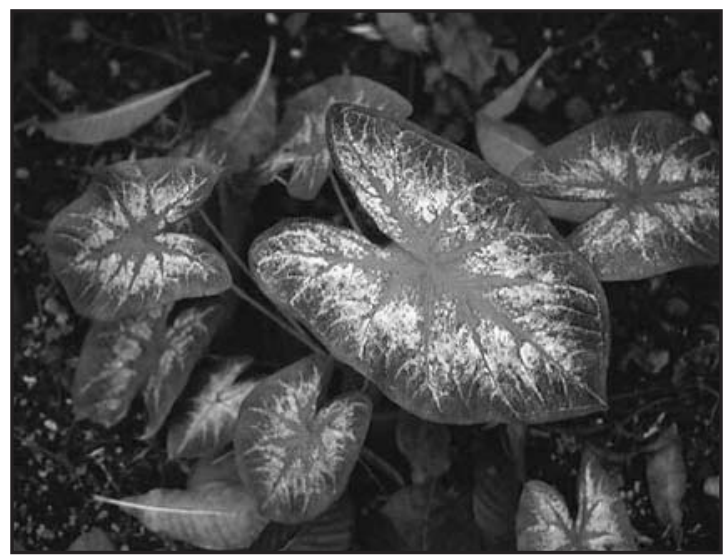

